\title{
Groundwater arsenic contamination in selected area of Bihar
}

\author{
S. Kumari ${ }^{1}$, A.K. Ghosh ${ }^{2}$, D. Mondal ${ }^{3}$, S. Suman ${ }^{4}$, P. Sharma ${ }^{4}$, P. Kumari ${ }^{2}$, N. Bose ${ }^{4}$ \& S.K. Singh ${ }^{4}$ \\ ${ }^{1}$ B.R.A. Bihar University, Muzaffarpur, Bihar, India \\ ${ }^{2}$ Mahavir Cancer Institute and Research Center, Patna, India \\ ${ }^{3}$ School of Environment \& Life Sciences, University of Salford, Salford, UK \\ ${ }^{4}$ Department of Geography, A.N. College, Patna, India
}

\begin{abstract}
Arsenic (As) is more concentrated near river plain of Bihar, like Ganga and Gandak rivers. It is not reported in places where fluoride content is high in ground water. The current study observed high As contents in the alluvial aquifer of Ganga basin, but no As in hard rock area away from Ganga like Banka district of Bihar.
\end{abstract}

\section{INTRODUCTION}

Arsenic (As) is an element, which is highly toxic in nature. The occurrence of As in ground water was first reported in 1980 in West Bengal in India. Groundwater is the main source of drinking water and constitutes about more than $80 \%$ drinking source in rural Bihar. The groundwater As contamination in Bihar was first reported in Semaria Ojha Patti village of Shahpur, a block of Bhojpur district in 2002 (Chakraborti et al., 2003). So far, 17 of 37 districts and a total of 87 of 532 community blocks have been investigated for groundwater As contamination. Three community blocks were As safe, as all the sources tested in these blocks had As levels below the detection limit of the measurement method used (Ghosh et al., 2009). Currently, the groundwater As contamination has spread to 16 districts, threatening more than 10 million people in Bihar (Ghosh et al., 2007). Out of a total 240,000 water supply hand pumps (public and private) in As affected blocks of Bihar, only $27 \%(66,623)$ of the sources were tested for elevated As levels (Nickson et al., 2007). The continuous consumption of As through drinking water and food sources may lead to As poisoning popularly known as 'Arsenicosis'. The United States National Research Council has reported that, one in 10 people who drink water containing $500 \mu \mathrm{g} \mathrm{L}^{-1}$ of As may ultimately develop lung, bladder, and skin cancers. Arsenic health effects range from skin lesions to cancer at values from $10 \mu \mathrm{g} \mathrm{L}^{-1}$ to up to $2000 \mu \mathrm{g} \mathrm{L}^{-1}$ of As in drinking water.

\section{METHODS}

\subsection{Study area}

Samples $(\mathrm{N}=42)$ were collected from volunteers residing in As contaminated areas from Bhagalpur (Rannuchak and Nandgola), Banka (Rajpura and Kakna), Saran (Sabalpur), Patna (Haldi Chapara,
Maner) and Samastipur (hanssopur) districts of Bihar, India as a part of ongoing Nutri-SAM project.

\subsection{Data collection}

After taking informed consent, data on socioeconomic, nutritional and health status were collected using questionnaire. Water sample were collected and As content was estimated by Atomic Absorption Spectrophotometer (PerkinElmer PinAAcle 900 T) using standard APHA protocol.

\subsection{Analysis method of water}

Sterilized bottles were used for collection of water sample in which 6-10 drops of $1 \% \mathrm{HNO}_{3}$ was added as preservative in each sample bottle. Water samples were collected after 10-15 minutes of flushing the hand pump. Sample bottle were filled up to neck. Samples were brought to lab and stored in refrigerator at $5^{\circ} \mathrm{C}$. Arsenic content was analyzed by AAS.

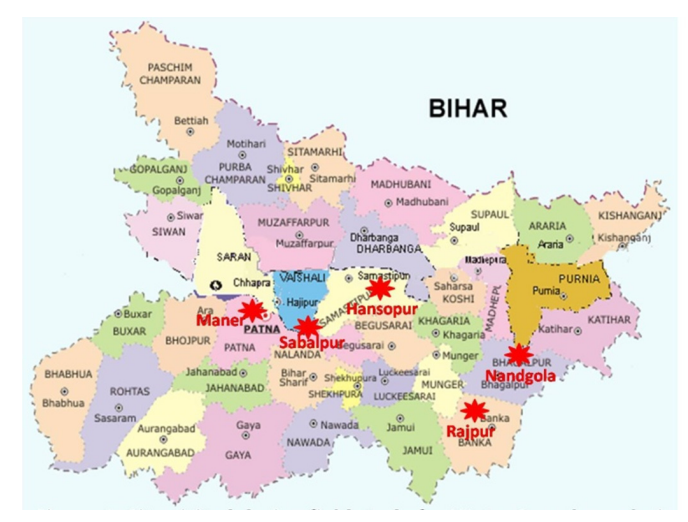

Figure 1. Site visited during field study for water sample analysis. 


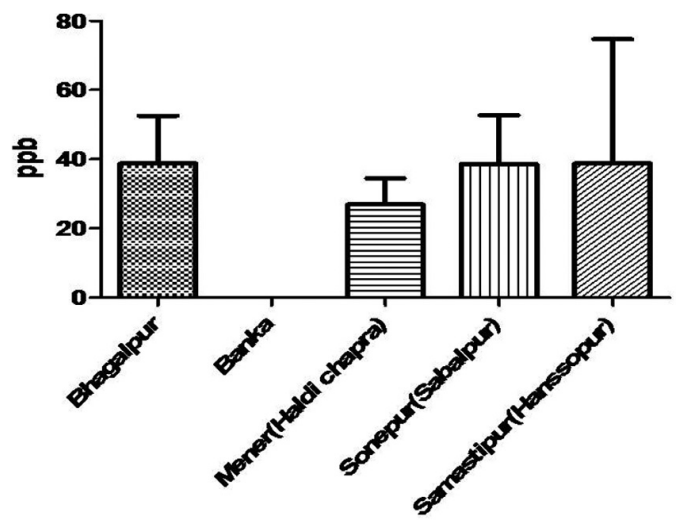

Figure 2. Arsenic level in water samples.

Table 1. Summary of arsenic concentrations $\left(\mu \mathrm{g} \mathrm{L}^{-1}\right)$.

\begin{tabular}{llcl}
\hline Area & Mean & SEM & Maximum \\
\hline Bhagalpur & 38.79 & 13.75 & 99.47 \\
Banka & 00 & 00 & 00 \\
Mener (Haldi Chapra) & 26.88 & 7.527 & 50.62 \\
Sonepur (Sabalpur) & 38.62 & 14.09 & 107.1 \\
Samastipur (Hanssopur) & 38.74 & 35.96 & 254.5 \\
\hline
\end{tabular}

\subsection{Statistical analysis}

Descriptive data as mean \pm standard deviation along with comparison tests, association and correlations represented using Graph Pad Prism was done.

\section{RESULTS AND DISCUSSION}

\subsection{Arsenic level in water samples}

There were significant differences between As level in water of different study site. Mean \pm SEM of As level in Bhagalpur was $38.79 \pm 13.75 \mu \mathrm{g} \mathrm{L}^{-1}(\mathrm{n}=11)$, mean \pm SEM of As level in Maner (Haldi Chapra) was $26.88 \pm 7.53 \mu \mathrm{g} \mathrm{L}^{-1}(\mathrm{n}=7)$, mean \pm SEM of As level in Sonepur (Sabalpur) was 38.62 $\pm 14.09 \mu \mathrm{g}$ $\mathrm{L}^{-1}(\mathrm{n}=8)$, mean \pm SEM of As level in Samastipur (Hanssopur) was $38.74 \pm 35.96 \mu \mathrm{g} \mathrm{L}^{-1}(\mathrm{n}=7)$.

High As concentration was observed at 50 to $140 \mathrm{ft}$ depth, while groundwater samples below $250 \mathrm{ft}$ had no As in this area. There was no significant difference in demography and nutrient intake between participants. Skin pigmentation and keratosis were reported in low socioeconomic people residing in these areas, while with high socio economic status have little or no symptoms, which indicates that nutritional supplement has a great role in detoxification of As toxicity.

\section{CONCLUSIONS}

It is concluded from study that As is more concentrated near river plain of Bihar, like Ganga and Gandak rivers. It is not reported in places where high fluoride content is reported for example Banka district but has no As.

\section{ACKNOWLEDGEMENTS}

This study is funded by the DST-UKIERI Thematic partnership project. We thank all the participants.

\section{REFERENCES}

Chakraborti, D., Mukherjee, S.C., Pati, S., Sengupta, M.K., Rahman, M.M. \& Chowdhury, U.K. 2003. Arsenic groundwater contamination in middle Ganga plain, Bihar, India: A future danger. Environ. Health Persp. 111(9): 1194-201.

Ghosh, A.K., Singh, S.K., Bose, N., Roy, N.P., Singh, S.K., Upadhyay, A.K., Kumar, S. \& Singh A. 2009. Arsenic hot spots detected in the state of Bihar (India): A serious health hazard for estimated human population of 5.5 lakhs. In Assessment of Ground Water Resources and Management, I.K. International Publishing House Pvt. Ltd., New Delhi, India., 62-70.

Ghosh, A. K., Singh, S.K., Bose, N., Singh, S.K., Singh, A., Chaudhary, S. Mishra, R., Roy, N.P. \& Upadhyaya, A. 2007. Study of arsenic contamination in ground water of Bihar (India) along the river Ganges. In: International Workshop on Arsenic Sourcing and Mobilization in Holocene Deltas. Department of Science and Technology, Government of India, pp. 83-87.

Nickson, R., Sengupta, C., Mitra, P., Dave, S.N., Banerjee, A. K., Bhattacharya, A., Basu, S., Kakoti, N., Moorthy, N. S., Wasuja, M., Kumar, M., Mishra, D.S., Ghosh, A., Vaish, D. P., Srivastava, A. K., Tripathi, R. M., Singh, S. N., Prasad, R., Bhattacharya, S. \& Deverill, P. 2007. Current knowledge on the distribution of arsenic in groundwater in five states of India. J. Environ. Sci. Heal. A, 42(12): 1707-1718. 